Sādhanā, Vol. 26, Part 5, October 2001, pp. 439-445. C Printed in India

\title{
A note on critical flow section in collector channels
}

\author{
SUBHASISH DEY \\ Department of Civil Engineering, Indian Institute of Technology, Kharagpur \\ 721 302, India \\ e-mail: sdey@ civil.iitkgp.ernet.in
}

MS received 13 November 2000; revised 20 May 2001

\begin{abstract}
Generalized solution for the location of critical flow section in collector channels is presented. Based on the concept of the singularity, the dynamic equation of spatially varied flow (SVF) is solved using the flow resistance equations of von Karman (for rough regime) and Jain (for transitional and smooth regimes). The advantage of using Jain's equations is that they provide the explicit forms of the Colebrook-White and Nikuradse equations. Computational steps for the determination of critical flow section in a collector channel, being dependent on channel geometry, roughness, longitudinal bed slope and inflow discharge, are given for different channel shapes.
\end{abstract}

Keywords. Collector channel; critical flow section; hydraulics; open channel flow; spatially varied flow.

\section{Introduction}

In a spatially varied flow (SVF), the flow discharge varies towards the downstream direction. For example, a collector channel collects surplus water through side-weirs of a storage system. From the point of view of practical interest, a collector channel, designed for having zero discharge at the upstream starting point, receives the lateral discharge at a constant rate per unit length of channel. With discharge increasing downstream in a collector channel, a critical flow section prevails where the flow changes from subcritical to supercritical. When a control section is known, the dynamic equation of SVF can be solved. Location of a control section is rather important to design channel depth.

Bremen \& Hager (1989) and Hager (1985) showed that the critical flow section could be determined with the aid of the singular-point method, if a critical flow section exists in collector channels. However, the critical flow section is dependent on channel characteristic parameters and lateral inflow discharge. An arbitrary selection of channel characteristic and flow parameters may result in supercritical flow even though a critical flow section does not exit. Guo (1999) and Dey (2000) put forward a set of design charts for the determination of critical flow section in trapezoidal and circular channels respectively, considering the Manning and Chezy equations. However, the use of flow resistance equations for rough,

A list of symbols is given at the end of the paper 
transitional and smooth regimes, being the most realistic and appropriate approach, has received no attention so far.

The aim of the present study is to report a methodology for generalized solution of critical flow section in collector channels. The solution is obtained using the flow resistance equations of von Karman (for rough regime) and Jain (1976) (for transitional and smooth regimes).

\section{The model}

The discharge in a collector channel, having zero inflow at the starting point upstream, is the product of the constant lateral inflow discharge per unit length and the length of the channel from the starting point upstream to the section of interest. Thus, one can write

$$
Q=q x,
$$

where $Q=$ discharge at distance $x$ measured from the starting point upstream, and $q=$ lateral inflow discharge per unit length. According to Chow (1959), in case of the lateral flow being normal to the collector channel (assuming hydrostatic pressure and uniform velocity distribution), the dynamic equation of an SVF is written in terms of the variation of free surface profile

$$
\frac{\mathrm{d} y}{\mathrm{~d} x}=\frac{S_{o}-S-2(h / x) \mathrm{Fr}^{2}}{1-\mathrm{Fr}^{2}},
$$

where $y=$ flow depth, $S_{o}=$ channel bed slope, $S=$ friction slope, $h=$ hydraulic depth $(=A / T), A=$ flow area, $T=$ top width of flow, and $\mathrm{Fr}=$ Froude number of flow. The Froude number is given by

$$
\operatorname{Fr}=(Q / A) /(g h)^{1 / 2}=Q(T)^{1 / 2} /\left(g A^{3}\right)^{1 / 2},
$$

where $g=$ gravitational constant.

Solution of (2) can be obtained using a tail water condition or control section. The present analysis deals with the case where the discharge increases downstream resulting in a change of flow regime from subcritical to supercritical in an SVF. However, the critical flow section serves as a control section. Thus, (2) is applied to the critical flow section, where Froude number $\mathrm{F}$ is unity. Thus, one gets

$$
S_{o}-S_{c}-2\left(h_{c} / x_{c}\right)=0 \text {. }
$$

In the above, subscript $c$ refers to the parameters associated with the critical flow section. At the critical flow section, (3) becomes

$$
Q_{c}=\left(g A_{c}^{3} / T_{c}\right)^{1 / 2} .
$$

The location of the critical flow section xc can be obtained using (1) and (5) as

$$
x_{c}=\left(g A_{c}^{3} / q^{2} T_{c}\right)^{1 / 2} \text {. }
$$

As no physical solution can be obtained from (4) [conditions for no solution have been discussed by Dey $(1994,1998)]$ for certain design parameters, designers find it difficult to confirm the existence of a critical section without any mathematical guidance. To 
establish such guidance for obtaining feasible solution of (4), substituting (6) into (4) and normalizing, one gets

$$
\left(S_{c} / S_{o}\right)+\left[2 \hat{q} /\left(\hat{T}_{c} \hat{A}_{c}\right)^{1 / 2}\right]=1
$$

where $\hat{q}=q /\left(S_{o} g^{0.5} l^{1.5}\right), \hat{T}=T / l, \hat{A}=A / l^{2}$, and $l=$ length parameter of channel. Also, (6) can be expressed as a normalized form as

$$
\hat{x}_{c}=\left(\hat{A}_{c}^{3} / \hat{T}_{c}\right)^{1 / 2} / \hat{q},
$$

where $\hat{x}=x S_{o} / l$. Henderson (1966) derived $S_{c}$ using the Chezy equation. French (1985) obtained the solution for wide channels following the Henderson method. In the present study, the term $S_{c}$ is determined using the flow resistance equations of von Karman (for rough regime) and Jain (1976) (for transitional and smooth regimes).

\subsection{Rough regime}

For a complete rough regime, the von Karman equation of flow resistance can be used for the determination of friction slope $S_{c}$, as was done by Dey $(1998 \mathrm{a}, \mathrm{b})$. It is important to mention that the ASCE Task Force (1963) on the friction factor in open channels recommended that, for open channel roughness similar to that encountered in pipes, flow resistance equations similar to those of pipe flow are adequate for the estimation of friction factor. The von Karman equation is

$$
1 / \lambda^{1 / 2}=1.14-0.86 \ln \left(k_{s} P_{c} / 4 A_{c}\right),
$$

where $\lambda=$ friction factor, $k_{s}=$ Nikuradse equivalent sand roughness, and $P=$ wetted perimeter. The friction factor can be extracted from the equation of bed shear as

$$
\tau=(\lambda / 8) \rho\left(Q_{c} / A_{c}\right)^{2}=\gamma\left(A_{c} / P_{c}\right) S_{c},
$$

where $\tau=$ bed shear stress, $\rho=$ mass density of fluid, and $\gamma=$ specific weight of fluid. Using (9) and (10), one can write

$$
S_{c}=P_{c} Q_{c}^{2} / 8 g A_{c}^{3}\left[1.14-0.86 \ln \left(K_{s} P_{c} / 4 A_{c}\right)\right]^{2} .
$$

Replacing $Q_{c}$ from (5) into (11) and normalizing, yields

$$
S_{c}=\hat{P}_{c} / 8 \hat{T}_{c}\left[1.14-0.86 \ln \left(\hat{k}_{s} \hat{P}_{c} / 4 \hat{A}_{c}\right)\right]^{2},
$$

where $\hat{P}=P / l$, and $\hat{k}_{s}=k_{s} / l$.

\subsection{Transitional regime}

In transitional regime, the Colebrook-White equation is applicable. The advantage of using the Colebrook-White equation is that it covers the regime of flow from hydraulic smooth regime to rough regime. The rough or smooth regime can be verified from the values of relative roughness $\varepsilon\left(=0.25 k_{s} P A^{-1}\right)$ and flow Reynolds number $\operatorname{Re}\left(=4 Q P^{-1} n^{-1}\right.$; where $v=$ kinematic viscosity being assumed as $10^{-6} \mathrm{~m}^{2} / \mathrm{s}$ ) using the well-known Moody 
Table 1. Parameters of different channel sections.

\begin{tabular}{lccc}
\hline$l$ & $\hat{A}$ & $\hat{P}$ & $\hat{T}$ \\
\hline Trapezoidal channel & $\hat{y}\left[1+(\hat{y} / 2)\left(m_{l}+m_{r}\right)\right]$ & $1+\hat{y}\left(1+m_{l}^{2}\right)^{1 / 2}+\left(1+m_{r}^{2}\right)^{1 / 2}$ & $1+\hat{y}\left(m_{l}+m_{r}\right)$ \\
$b$ & $0.25\left[\cos ^{-1}(1-2 \hat{y})-2(1-2 \hat{y})\right.$ & $\cos ^{-1}(1-2 \hat{y})$ & $2(\hat{y}(1-\hat{y}))^{1 / 2}$ \\
Circular channel & $\left.(\hat{y}(1-\hat{y}))^{1 / 2}\right]$ & & \\
$d$ & & & \\
\hline
\end{tabular}

Note: In the above, $b=$ channel width, $m_{l}=$ left side slope, $m_{r}=$ right side slope, $d=$ channel diameter, and $\hat{y}=y / l$.

diagram. However, as the Colebrook-White equation is an implicit equation of $\lambda$, the use of flow resistance equation proposed by Jain (1976), which is the explicit from of the Colebrook-White equation, makes the solution simpler. The explicit form of the Colebrook-White equation is also reported elsewhere (Churchill 1977; Chue 1984; Chen 1985). The equation of Jain (1976) is

$$
\frac{1}{(\lambda)^{1 / 2}}=1.14-0.86 \ln \left(\left(k_{s} P_{c} / 4 A_{c}\right)+\left(6.1 v^{0.9} P_{c}^{0.9} / Q_{c}^{0.9}\right)\right) \text {. }
$$

Using (5) and (10), (13) is expressed in normalized form as

$$
S_{c}=\frac{\hat{P}_{c}}{8 \hat{T}_{c}\left[1.14-0.86 \ln \left(\left(\hat{k}_{s} \hat{P}_{c} / 4 \hat{A}_{c}\right)+\left(6.1 \beta^{0.9} \hat{P}_{c}^{0.9} \hat{T}_{c}^{0.45} / A_{c}^{1.35}\right)\right)\right]^{2}}
$$

where $\beta=v /\left(g^{0.5} l^{1.5}\right)$.

\subsection{Smooth regime}

The complete smooth regime is seldom obtained in practice. The channel is considered to be smooth when the roughness elements are submerged by the laminar-sublayer. The Nikuradse equation is applicable in smooth regime. As his equation is an implicit equation of $\lambda$, Jain (1976) also proposed an explicit form of the Nikuradse equation. The equation is

$$
\frac{1}{(\lambda)^{1 / 2}}=0.78 \ln \left(4 Q_{c} / v P_{c}\right)-1.5146
$$

Using (5) and (10), (15) is expressed in normalized form as

$$
S_{c}=\hat{P}_{c} / 8 \hat{T}_{c}\left[0.78 \ln \left(4 A_{c}^{1.5} / \beta \hat{P}_{c} \hat{T}_{c}^{0.5}\right)-1.5146\right]^{2} .
$$

\section{Common channel sections}

The channel parameters of some commonly available channels in practice, required for the direct use in the developed equations of the preceding section, are furnished in table 1. Hence, the two extreme cases of trapezoidal channel section are rectangular $\left(m_{l}=m_{r}=0\right)$ and triangular $(b=0)$ sections. 


\section{Computational steps}

The equations developed in the preceding section are used to design a collector channel. As input data, the values of $q, S_{o}, k_{s}$ and other channel characteristic parameters, such as for the rectangular channel $b$, the trapezoidal channel $b, m_{l}$ and $m_{r}$, and the circular channel $d$. The steps involved for the computation are given below.

(1) Compute $\hat{q}, \hat{k}_{s}$ and $\beta$.

(2) Consider complete rough regime. Substitute $S_{c}$ from (12) in (7).

(3) Compute $\hat{y}_{c}$ numerically, using the Muller method (Conte \& de Boor 1987).

(4) Compute $\hat{A}_{c}, \hat{P}_{c}$ and $\hat{T}_{c}$.

(5) Using (8), compute $\hat{x}_{c}$.

(6) Compute $x_{c}\left(=\hat{x}_{c} l / S_{o}\right)$.

(7) Compute $\varepsilon$ and Re.

(8) Using the Moody diagram, check the hydraulic regime considered in step 2.

(9) If agreeable to the consideration in step 2, stop computation. Otherwise, in step 2, use (14) or (16) in place of (12) and repeat steps 2 to 8 .

\section{Numerical illustration}

To illustrate the application of the computational steps for designing a collector channel, the following numerical example is considered. The input data for a trapezoidal channel are: $q=3.72 \mathrm{~m}^{2} / \mathrm{s}, S_{o}=0.15, k_{s}=0.01 \mathrm{~m}, b=3 \mathrm{~m}$, and $m_{l}=m_{r}=0.5$. The value of $x_{c}$ is to be determined.

Using the given data, $\hat{q}=1.524, \hat{k}_{s}=3.333 \times 10^{-3}$, and $\beta=6.144 \times 10^{-8}$, and considering the complete rough regime, $S_{c}$ is substituted from (12) in (7). The value of $\hat{y}_{c}$, computed numerically using the Muller method (Conte \& de Boor 1987), is found to be 1.828 . Then, $\hat{A}_{c}, \hat{P}_{c}$, and $\hat{T}_{c}$ are computed as $3.5,5.088$ and 2.828 respectively. Using (8), $\hat{x}_{c}$ is obtained as 2.554 and $x_{c}\left(=\hat{x}_{c} l / S_{o}\right)$ is $51.083 \mathrm{~m}$. The hydraulic regime, checked for $\varepsilon=0.00121$ and $\operatorname{Re}=4.01 \times 10^{6}$ using the Moody diagram, confirms that the initial assumption of complete rough regime is valid.

\section{Conclusions}

Based on the concept of the singular-point, the dynamic equation of an SVF has been solved using the flow resistance equations of von Karman (for rough regime) and Jain (for transitional and smooth regimes) to derive a generalized solution for critical flow section in collector channels. The computational steps for the determination of critical flow section in SVF have been given for different channel shapes.

The writer is grateful to Mr Bimalundu Dey for his helpful suggestions during the preparation of the paper. 


\section{List of symbols}

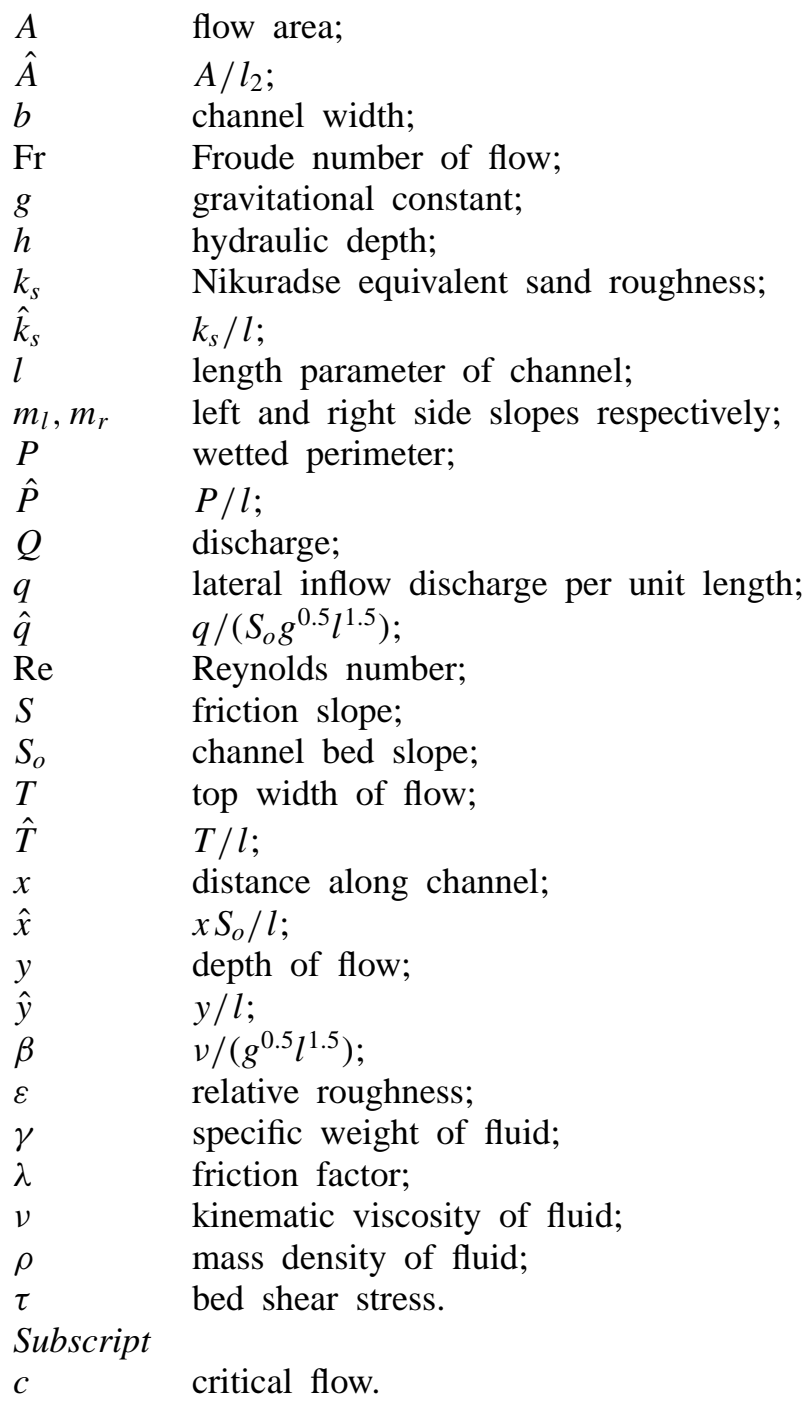

\section{References}

ASCE Task Force 1963 Friction factor in open channels. J. Hydraul. Div., Am. Soc. Civ. Eng. 89: 97-143

Bremen R, Hager W H 1989 Experiments in side-channel spillways. J. Hydraul. Eng., Am. Soc. Civ. Eng. 115: 617-635

Chen J J J 1985 Systematic explicit solutions of the Prandtl and Colebrook-White equations for pipe flow. Proc. Inst. Civ. Eng. (London) 79: 383-389

Chow V T 1959 Open channel hydraulics (New York: McGraw-Hill)

Chue S H 1984 A pipe skin friction law of universal applicability. Proc. Inst. Civ. Eng. (London) 77: 43-48 
Churchill S W 1977 Friction factor equation spans all fluid regimes. Chem. Eng. 84: 91-92 Conte S D, de Boor C 1987 Elementary numerical analysis: an algorithmic approach (New York: McGraw-Hill)

Dey S 1994 No-choke flow in trapezoidal channels. J. Eng. Mech., Am. Soc. Civ. Eng. 120: 2224-2231

Dey S 1998a Free overfall in rough rectangular channels: a computational approach. Water, Maritime and Energy, Proc. Inst. Civ. Eng. (London) 130: 51-54

Dey S 1998b End depth in circular channels. J. Hydraul. Eng., Am. Soc. Civ. Eng. 124: 856-863

Dey S 1998c Choke-free flow in circular channels with increase in bed elevations. J. Irrig. Drain. Eng., Am. Soc. Civ. Eng. 124: 317-320

Dey S 2000 Critical section of flowing water in circular collector channels. Dam Eng. 11: 19-28

French R H 1985 Open channel hydraulics (New York: McGraw-Hill)

Guo J C Y 1999 Critical flow section in collector channel. J. Hydraul. Eng., Am. Soc. Civ. Eng. 125: 422-425

Hager W H 1985 Trapezoidal side-channel spillways. Can. J. Civ. Eng. 12: 774-781

Henderson F M 1966 Open channel flow (New York: Macmillan)

Jain A K 1976 Accurate explicit equation for friction factor. J. Hydraul. Div., Am. Soc. Civ. Eng. 102: 674-677 